\title{
El niño Fiscal como Autoridad Tradicional Comunal en Santa Cruz de lla
}

\section{Attorney child as Traditional Authority Community in Santa Cruz de lla}

\author{
Condor Ames, Juan Carlos \\ Facultad de Antropología, Universidad Nacional del Centro del Perú
}

\section{RESUMEN}

La comunidad campesina de Santa Cruz de lla, basa su estructura organizacional en la comunidad, este centro poblado se encuentra ubicado al sureste del distrito de Pazos, de la provincia de Tayacaja, Región Huancavelica, se encuentra a una altitud de 3658 m.s.n.m. Siendo su actividad principal el cultivo de maíz y otros cereales, además de la papa en sus distintas variedades. Dentro del patrimonio inmaterial comunal se encuentran las diversas fiestas patronales, siendo la principal la del 8 de octubre alusiva a la Virgen del Rosario y la fiesta alusiva al Niño Jesús el 26 de Diciembre de cada año. En tanto el sistema de autoridades está consignado bajo el régimen comunal, constituyendo el niño fiscal una autoridad tradicional comunal en este centro poblado, constituyéndose en un autoregulador de la vida organizacional de esta comunidad.

Esta festividad del Niño Jesús funciona a través del sistema de cargos que está esta ritualizado para ir ejercitando a los niños a partir de los 7 años en el proceso iniciático como futura autoridad en el orden comunal.

La acción rituálica de los niños fiscales obedecen a una determinada etapa cíclica del calendario agrícola solar al que denominan el año Wuata durante el mes de marzo, tiem-

\section{ABSTRACT}

The rural community of Ila boasts having in its context as a first-order organizational structure under the concept of community is central town of Santa Cruz de lla is located southeast side Pazos district, province Tayacaja, Huancavelica Region a altitude of $3658 \mathrm{~m}$ its main activity is the cultivation of maize and related cereals and potatoes in different varieties intangible heritage within the community are the various employers, the main one being 8 alluding to the Virgin of the Rosary October and allusive party to child Jesus on December 26 of each year. While the system of authority is disclosed under the communal system constituting a traditional communal child tax authority mentioned in this population center, forming a self-regulating the organizational life of the community of Santa Cruz de lla.

This festival through this ritualized cargo system to go exercising children from 7 years later in the initiation process for future authority in the communal order.

The rituálica share of tax Children obey a certain cyclical phase of the solar agricultural calendar which they call the year Wuata during March sacred time and associated recultivation corn Belt quintessential because it is located in the lower area between Quechua 
po sagrado y asociado al recultivo de maíz por ser zona maicera por excelencia debido a que se encuentra en la zona baja entre el piso quechua y chala, zona microclimática y templada dentro del ecosistema de la subcuenca del río Pazos.

Palabras clave: Fiscal, reciprocidad, comunidad, sistema de autoridades y faena comunal. and chala and warm microclimate within the ecosystem of the basin of the river Pazos area.

Keywords: Attorney, reciprocity, community, system and communal authorities slaughter.

\section{INTRODUCCIÓN}

La comunidad campesina de Santa Cruz de lla se encuentra ubicada en la parte baja del distrito de Pazos a una altitud de 3,464 msnm. Su estructura organizacional sigue siendo la comunal, es un centro poblado del distrito de Pazos. Cuenta con autoridades como el Agente y Teniente Gobernador; los comuneros activos, que en total son de 120 a 140 jefes de familia y 1600 habitantes, Cuenta con los siguientes barrios: Centro, San Cristóbal, los Cipreses y Rosas Pampa. Para la investigación las autoridades que fueron nuestros informantes son Eduardo Ávila de la Cruz y Lucio Ávila.

La población es Quechua hablante, las religiones que profesan mayormente son Adventistas y Católicos. Las principales actividades económicas constituyen la agricultura asociada con la pequeña ganadería. El cultivo predominante es la siembra de una variedad de maíz exquisita, y otros cereales como la cebada y las habas. En la parte más baja se siembra frutales y menestras como el friiol negro; tubérculos, papa, mashua, olluco y oca. Cuenta con manantiales para el consumo humano. Sus principales fiestas son "Los niños fiscales" en el mes de marzo y las "Fiestas de las Cruces" el 2 y 3 de mayo.

Por lo general cuando se trata de tener mayores precisiones acerca de alguna sociedad, en este caso de la comunidad campesina de lla anexo del distrito de Pazos de la provincia de Tayacaja - Huancavelica se piensa en sus patrones culturales aplicado a las actividades económicas y principalmente a la organización socio política de la estructura de esta, y además su forma de ver el mundo, de verse así mismo y de ver sus instituciones; muchas veces no se introduce en esta percepción el aspecto de la estructura organizacional ni espacial así como el tiempo dentro del calendario cíclico agrícola solar y las respectivas fases lunares. Se ha tomado en consideración, el tiempo en este mundo de los andes centrales como un espacio de un tipo de organización sui generis relacionado a un espacio festivo por lo mismo que son realidades inseparables (OSSI J: 16.17).

Los niños al asumir la responsabilidad de constituirse como autoridad tradicional comunal considerado "Niño Fiscal" es una forma de celebración en el campo político de ocupar, recorrer y representar los espacios, que las autoridades en su condición de adultos mayores asumen esta responsabilidad y en los niños estos mismos son los que motivan para que su función como tal, a través de la acción de los niños, sean ellos los encargados de hacer una réplica de lo que hacen los mayores al asumir tales roles y funciones como reproducción de la responsabilidad de los mayores.

El primer viernes de marzo es que los niños de la comunidad de Santa Cruz de lla asumen esta responsabilidad. Por tanto es importante hacer el seguimiento de esta función política que asumen los niños a temprana edad, aproximadamente desde los 9 años y como símbolo de constituirse autoridad. Sobre sus cuellos llevan un chicote de cuero prensado de camero con sus respectivos aros de metal que significan los grados que debe pasar durante un tiempo para 
llegar a constituirse como autoridad, dentro de los cánones democráticos de la comunidad legitimado por el estatuto comunal de Santa Cruz de lla.

\section{MATERIAL Y MÉTODOS}

Libreta de campo, informes, cámara fotográfica, grabadora, filmadora, pc, entrevistas, historias de vida y testimonios.

El método que se usó fue el etnográfico que permitió obtener datos de la comunidad de Santa Cruz de lla, que es conocida hace un buen tiempo por el investigador.

\section{RESULTADOS}

Esta es una comunidad que se encuentra en un proceso paulatino de fragmentación debido al proceso acelerado de migración de la zona rural a la ciudad, en esta época de la llamada globalización como lo afirma Mag Lujan, por la colonización del imaginario andino, a través de los hegemónicos medios de comunicación "brazo armado" de la modernidad como afirma el economista Javier Lajo en su obra: "Qapaqñan", ruta inca de la sabiduría. Estos cambios resultan como un martillo que minan la base de la estructura organizacional-comunal de Santa Cruz de lla, considerados (Ayllus del Ande) ésta fragmentación o individuación del tejido comunitario tiene una causa fundamental, y es la presencia de sectas religiosas, muy dogmáticas, que tipifican estas expresiones culturales como sinónimo de una acción demoniaca.

Sin embargo, estos hechos culturales ritualizados pueden considerarse una alternativa prospectiva desde épocas tempranas, cuya ceremonia religiosa-andina en este caso el rol de los "Niños Fiscales" en Santa Cruz de lla juega un rol muy importante para mantener la estructura organizacional-comunal en el quehacer de la vida cotidiana consuetudinaria de esta comunidad andina.

Lo que se ha encontrado en el centro poblado, bajo la estructura organizacional de comunidad campesina entre las zona quechua y chala, es que es una zona eminentemente maicera y asociado con otros cultivos como cereales en la parte más baja, y la zona que los campesinos denominan la cola del Huaytapallana, existen plantaciones de frutales, consecuentemente el concepto de comunidad pesa no solamente a nivel local sino también internacional y como antropólogo académico esto lo hemos podido evidenciar en los diversos países y universidades al que he sido invitado como académico visitante y conferencista con el tema la cosmovisión andina en los andes.

De lo explicado se infiere que los comuneros de Santa Cruz de lla siguen practicando las diversas formas de reciprocidad andina, del que hace un buen tiempo abordó el tema el antropólogo Enrique, estos resultados del enfoque de la cosmovisión andina están visibilizados en el proyecto de tecnologías andinas campesinas abordados por diversos profesionales tanto de las ciencias naturales como de las ciencias sociales cuya institución se denomina PRATEC, asimismo los resultados guardan estrecha relación con nuestra participación en el entonces consejo Nacional de Poblaciones Indígenas y estamos conectados a nivel internacional con el Instituto Internacional de Derechos Legales en Defensa de los Pueblos Indígenas con sede en Costa Rica, lo descrito nos anima a seguir visibilizando y afirmando desde el enfoque de la cosmovisión andina la importancia del tema los "Niños Fiscales" como autoridades comunales en el Centro Poblado de Santa Cruz de lla del distrito de Pazos, Provincia de Tayacaja, Región Huancavelica.

\section{DISCUSIÓN}

La investigación está en función a los enfoques entre lo que es la cosmovisión andina que considera aspectos muy importantes abordados por el etnohistoriador antropólogo Tom Zuidema quien explica que sigue funcionando las parcialidades en los pueblos del ande, así como también el antropólogo Juan Ossio habla del mismo tema aseverando que estas parcialidades funcionan en los territorios de los Andes Peruanos, signado por la presencia de los Ayllus. $Y$ de otro lado el enfoque de occidente moderno donde solo toca el aspecto material y obvia el 
aspecto espiritual en tanto no existe la cuatriparticipación territorial ni la trifuncionalidad cosmogónica de los actores sociales.

\section{CONCLUSIONES}

1. El niño fiscal como autoridad tradicional comunal en Santa Cruz de lla es una forma de afirmar sus raíces etnoculturales como comuneros, y a la vez es un autoregulador de la vida organizacional de la comunidad campesina de lla.

2. El ser autoridad desde niños es una etapa cíclica dentro del calendario agrícola solar como proceso de iniciación rituálica para ir ejercitando y así los niños se proyecten como futuras autoridades en el orden comunal.

3. Considerando que la comunidad es una institución democrática las autoridades mayores como el agente teniente y fiscal son los encargados de delegar funciones a los niños fiscales para la realización de las faenas comunales convocando a toda la comunidad en la limpieza de los canales de regadío durante la semana santa, el sábado Gloria desde las 8 a 11 de la noche donde empieza las novenas de la Virgen del Rosario y luego después de haber velado durante toda la noche la imagen de esta virgen durante el día asumen la responsabilidad de ordenar y guiar los trabajos comunales de la limpieza de los canales indicados líneas antes.

4. La presencia de sectas religiosas adventistas generan una clara división con los católicos lo cual va alterando vulnerando y desmembrando subterráneamente las tradiciones y costumbres como son la fiesta de las faenas comunales bajo el mando de los niños fiscales debido a que son adjetivadas como festividades paganas demoniacas y satánicas.

5. Uno de los ámbitos más abandonados y menos comprendidos en el Perú, son la comunidades campesinas, que se encuentra ubicadas en las estribaciones de los andes en diferentes pisos ecológicos, como es el caso de la comunidad campesina Santa Cruz de lla.

6. La lógica andina, basada en la producción y la reciprocidad campesina, permite a las familias de menores recursos, alcanzar el ideal de autonomía y seguridad frente a las adversidades económicas.

7. La organización del trabajo en las familias campesinas de Santa Cruz de lla, obedece a una división natural por sexo y edad, tanto en el trabajo doméstico dentro de la parcela familiar y en el trabajo comunal

8. La producción agrícola de las familias tiene especialización en cuanto se refiere al cultivo de la papa cuya producción en un $50 \%$ es para la venta en el mercado.

9. Los instrumentos de trabajos predominantes son los tradicionales, con una utilización en menor escala del tractor, especialmente en labores de roturación de las tierras.

\section{REFERENCIAS BIBLIOGRÁFICAS}

1. Fuenzalida V. F. (1970a). La estructura de la comunidad de indígenas tradicionales. El campesino en el Perú. Perú problema Nro. 3, pp. 16-104. Lima: Moncloa Campodónico.

2. Poder, raza y etnia en el Perú contemporáneo. En el indio y el poder en el Perú. (1970b). Perú Problema Nro. 4, pp. 15-86. Lima: Moncla-Campodónico.

3. Goodenough W.H. (1970). Description and Comparison in Cultural Antropology. Chicago: Aldine Publishing Company.

4. Greaves T. (1972). The Andean Rural Proletarians. Antropological Quarterly 45, Nro. 2: 65-83.

5. Guamán Poma de Ayala F. (1936). La primera nueva crónica y buen Gobierno. París, France: Instituí d'Ethnologie.

6. Handleman H. (1975).Struggle in the Andes: Peasant Political Mobilization in Perú. Austin y London: Institute of Latin American Studies, The University of Texas Press.

7. Instituto Indigenista Interamericano. (1971). Estatuto de comunidades campesinas del Perú. Anuario Indigenista (México City) 5, Nro. 3: 191-208.

8. Lumbreras S, y Luis G. (1959). "Sobre los Chancas". En actas y trabajos del II congreso nacional de historia del Perú, I, 211 243. Lima: Centro de estudios históricos militares del Perú.

9. MAYER, E y DE LA CADENA, M. (1989). Cooperación y conflicto en la comunidad 
andina: Zonas de producción y organización social. Instituto de Estudios Peruanos. Lima Perú.

10. MONTEGUDO, C. (1987). Economía familiar y comunal campesina. Tesis. Pontificia Universidad Católica. Lima Perú.

11. OSSIO, J y MEDINA, O. (1985). Familia campesina y economía de mercado. Edit. CRESE. Lima Perú.

12. SANCHEZ, R s/f. El campesino pobre en la quebrada del Cunas: El caso de la Comunidad de Angasmayo. U.N.A. Lima Perú.

13. WOLF, E. (1971). Los campesinos. Editorial Barcelona.

14. (1975). Las luchas campesinas del Siglo XX. Editorial México, España, Argentina.

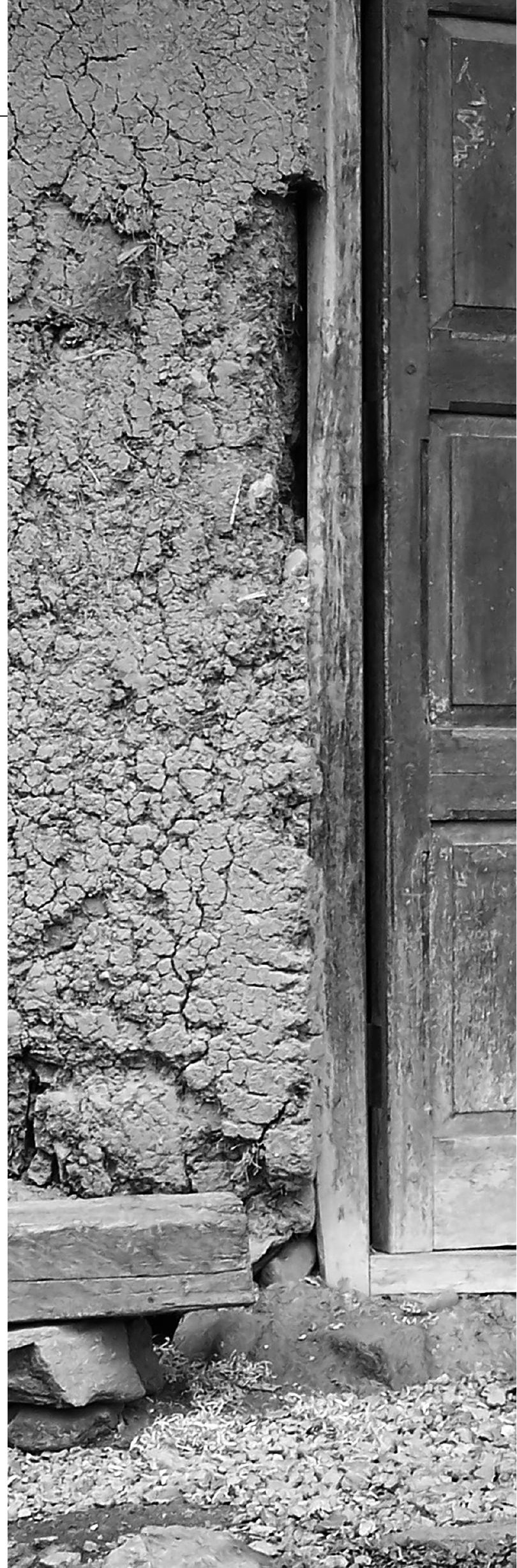

